\title{
The ecological community of commensal, symbiotic, and pathogenic gastrointestinal microorganisms - an appraisal
}

REVIEW

This article was published in the following Dove Press journal:

Clinical and Experimental Gastroenterology

5 May 2017

Number of times this article has been viewed

\author{
Seraj Zohurul Haque' \\ Mainul Haque ${ }^{2}$ \\ 'School of Medicine, University of \\ Dundee, Ninewells Hospital and \\ Medical School, Dundee, Scotland, \\ UK; ${ }^{2}$ Unit of Pharmacology, Faculty \\ of Medicine and Defense Health, \\ National Defense University of \\ Malaysia, Kem Sungai Besi, Kuala \\ Lumpur, Malaysia
}

\section{Video abstract}

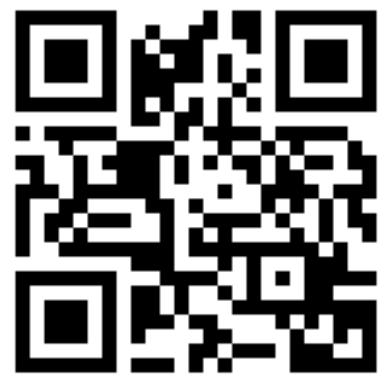

Point your SmartPhone at the code above. If you have a $Q R$ code reader the video abstract will appear. Or use: http://youtu.be/8r60nR8MDUo
Correspondence: Mainul Haque Unit of Pharmacology, Faculty of Medicine and Defense Health, National Defense University of Malaysia, Kem Sungai Besi, 57000 Kuala Lumpur, Malaysia

Tel +60 I 09265543

Email runurono@gmail.com

\begin{abstract}
The human gastrointestinal tract is inhabited by a vast population of bacteria, numbering 100 trillion. These microorganisms have been shown to play a significant role in digestion, metabolism, and the immune system. The aim of this study was to review and discuss how the human body interacts with its gut microbiome and in turn the effects that the microorganisms have on its host, overall resulting in a true mutualistic relationship.
\end{abstract}

Keywords: gastrointestinal, commensal, symbiotic, pathogenic microorganisms

\section{Introduction}

The word "microbiome" was first coined by American Molecular Biologist Dr Joshua Lederberg to imply the environmental and biological community of commensal, symbiotic, and pathogenic microorganisms that share human body space and have been all but ignored as elements of health and disease. ${ }^{1}$ The microbiome is defined as the overall collection of microbiota that resides inside humans or on their skin surface..$^{2-5}$ It has been recognized for some time that the human body is colonized by at least ten times more bacteria than the figure of human cells in the body and that most of these bacteria live in the human gastrointestinal (GI) territory. ${ }^{6-8}$ It has been estimated that $\sim 10-100$ trillion commensal bacteria occupy the human GI tract; therefore, the figure that vastly outnumbers the number of cells of human origin. ${ }^{5,89}$ Nevertheless, "the total cell number of a human being ranges between $10^{2}$ and $10^{16}$ and it is widely mentioned without a proper reference." ${ }^{10}$ In a recent report, it was found that "the number of cells in the human microbiota is likely to be highly variable depending on nutritional input, body size, age, ethnicity, culture, and environment." 11 Although worldwide most research has concentrated on microorganisms that cause disease and microbial drug resistance, due to unknown reasons, studies on the microbiome and their its benefits in the human body did has not had a similar prioritisation or urgency as those on pathogenic microorganismsin many communities and countries. ${ }^{7,12-19}$ There are an innumerable variety of microorganisms in nature, many of which can cause diseases in humans. However, the human body is a host to a great number and assortment of bacteria, viruses, ${ }^{20}$ and fungi, ${ }^{21}$ which are beneficial to health and well-being. It has been reported that the normal inhabitant bacterial flora of the human body is poorly understood. ${ }^{22-25}$ Although they are termed commensals, bacteria comprising the gut microbiome share a much stronger relationship with the human host than the term suggests. ${ }^{26-29}$ Commensalism is a form 
of symbiosis whereby one organism gains from its association with another organism, whereas the other is affected in neither a positive nor a deleterious manner. There is more of a mutualistic nature to the bond shared by human host and bacterial colonizers in that the relationship benefits both parties: the microbiome is provided with an environment to live in and a readily available source of nutrients, and the human receives metabolites from bacterial digestion which it could not have otherwise obtained. ${ }^{29-31}$ As the human hostages, the gut microbiome gains a level of stability that suggests a strong interrelationship between host and bacteria, which has evolved over a substantial period. ${ }^{32,33}$ In addition, in the process of digestion and metabolism, these bacteria play an important role in the immune system and other body functions. ${ }^{34,35}$ Over the last 20 years, it has been shown that it is possible to modulate the composition and metabolic activities of the gut microbiome such that the health benefits to the host are maximized while reducing the deleterious effects of pathogenic organisms. ${ }^{34,36-39}$ This has made the study of the microbiome a subject of great interest.

\section{Anatomy of the gut and bacterial compositions}

The GI tract starts at the mouth, connects to the esophagus and thence to the stomach and small and large intestines, and ends at the rectum. The GI tract can be visualized as a long tube that passes uninterrupted through the body from lips through to anus. The stomach, small bowel, and colon are the organs that constitute the gut. The large intestine is the most densely populated section of the GI tract. The stomach contains relatively low numbers of bacteria, primarily due to the acidic nature of gastric juice. Stomach contents are also retained for a relatively short time; therefore, the food supply for bacteria is limited. Despite this fact, microbial populations in the stomach can reach $10^{3}$ organisms per gram of contents, rising to $10^{6} / \mathrm{g}$ after a meal, due to the buffering capacity of food. ${ }^{40,41}$ The predominating microbial species are acid-tolerant lactobacilli and streptococci, which can withstand a low-pH environment to some extent. ${ }^{41}$ Bacteria are considerably more numerous in the distal small bowel and large intestine. The transit of contents through the colon takes considerably longer time, which provides time for complex microbial communities to develop. ${ }^{42}$ Currently, the microbe population living in the human intestine is named "gut microbiota" (previously known as "gut flora"). ${ }^{43}$ Human gut microbiota comprises tens of trillions of microorganisms, counting at least 1,000 different species of known bacteria with more than three million genes (150 times more than human genes). ${ }^{43,44}$ The most abundant species belong to the phyla Bacteroidetes and Firmicutes, which account for up to $90 \%$ of all the bacteria in the distal gut. ${ }^{45}$ Human intestine accommodates multifarious-community microbial cells that have an impact on humanoid "physiology, metabolism, nutrition and immune function while disruption to the gut microbiota has been linked with GI conditions such as inflammatory bowel disease (IBD) and obesity." ${ }^{37}$

\section{Digestion in the human gut}

It was traditionally considered that the main function of the large intestine was principally the reclamation of water and salts and that it had little or no role in digestive processes, which occurred in the stomach and small intestine. However, it has been shown that a small, but significant contribution is made to digestive processes by the large gut, as modulated by the microbiome.

\section{Carbohydrate digestion}

Carbohydrate catabolism (and, to a lesser extent, protein breakdown) yields short-chain fatty acids (SCFAs), and this is done by a process called fermentation, which is conducted by anaerobic bacteria in the gut. ${ }^{46}$ Carbohydrates that can be grouped under the term "dietary fibers" are the most common sources of SCFAs, as well as starches that are not digested in the small intestine. ${ }^{47,48}$ Dietary fibers are indigestible in humans; therefore, the fermenting actions of the gut microbiota generate SCFAs for human use. The three principal SCFAs found in the human body are butyrate, propionate, and acetate, in an approximate ratio of $1: 1: 3 .{ }^{49}$ Approximately $95 \%-99 \%$ (the clear majority) of SCFAs produced in the gut are absorbed. ${ }^{50}$ SCFAs, predominantly butyrate, are vital sources of energy for colonocytes, and up to $70 \%$ of their energy needs may be gained through fermentation. ${ }^{41}$ It has been shown in mice that a lack of a microbiome, and therefore no production of butyrate, can lead to autophagy (self-digestion of cells in response to an energy and nutrient deficit) of the colon cells., ${ }^{9,51,52}$ The colonocytes of these germ-free mice were also found to be energy-deficient, as well as having reduced levels of enzymes that catalyze reactions such as those in the citric acid cycle. ${ }^{51}$ This highlights the importance of a microbiome and the substantial contribution they make to energy supply. The SCFAs are useful energy sources as well as playing a role in the human immune system. A recent study detected that SCFAs also regulate the immune system and inflammatory response. ${ }^{52}$ They diminish the sensitivity of lamina propria macrophages to commensal bacteria, via nitric oxide, IL-6, and IL-12 independent of 
free fatty acid receptor signaling, to persuade tolerance. ${ }^{53}$ The SCFAs, especially propionate and butyrate, have also been shown to inhibit the expression of lipopolysaccharideinduced cytokines, IL-6 and IL-12p40, in human mature dendritic cells.${ }^{54}$ The SCFAs, which were used therapeutically in inflammatory diseases in a controlled experimental setup, showed improvements in IBD and acute radiation proctitis, as it plays a direct anti-inflammatory role. ${ }^{55-57}$ Propionate and acetate have been found to show an anti-inflammatory action on human monocytes by regulating cytokine and chemokine production, such as IL-10 and MCP- $1 .{ }^{58} \mathrm{MCP}-1$ is one of the key chemokines that regulate migration and infiltration of monocytes/macrophages..$^{59}$ Propionate and butyrate have also exhibited anticancer properties. ${ }^{60,61}$

\section{Protein digestion}

The breakdown of protein by the gut microbiota also contributes to SCFA production, but not as profoundly as carbohydrate fermentation. However, this process releases a greater variety of end products such as hydrogen, carbon dioxide, ammonia, thiols, amines, indoles, and phenols. Many of these substances are considered toxic and have carcinogenic effects. Thus, protein catabolism is a less beneficial process compared with carbohydrate fermentation. ${ }^{41}$ It can be noted that many large bowel diseases occur in the distal gut (ie, the descending and sigmoid colons). As food passes along the bowel, the most easily digestible material (carbohydrates) will be used up first; therefore, protein digestion becomes more important in the distal sections. Signature products of amino acid breakdown are branched-chain fatty acids (BCFAs), and it was found by the experiments conducted with human sudden death victims that the concentrations of BCFAs were notably higher in gut contents obtained from the distal large bowel than that of the proximal colon. SCFAs, produced during protein digestion, more than doubled from $17 \%$ to $38 \%$ in the distal large gut. This evidence points to protein breakdown and the production of toxic by-products as potential causes of diseases in the distal large gut. ${ }^{41}$

\section{Modulation of the microbiome}

As it is well established that a healthy gut microbiome has many positive effects on their human hosts and has influence on diseases, thoughts have turned to how to change and enhance the microbiome to gain further health benefits.

\section{Prebiotics}

A prebiotic is defined as a nonviable food component that confers a health benefit on the host associated with the modulation of the microbiota. ${ }^{62,63}$ Although most foodstuff will change the levels of bacteria in the gut, ${ }^{64}$ nonviable food ingredients such as inulin, fructo-oligosaccharides, and galacto-oligosaccharides have a more specific effect on the growth of beneficial bacteria, such as bifidobacteria and lactobacilli. ${ }^{65}$ Both are gram-positive anaerobes, which are specialized in the breakdown of carbohydrates in the gut. ${ }^{66} \mathrm{As}$ mentioned above, carbohydrate digestion produces SCFAs, which is beneficial to the gut. A few negative effects of prebiotics have been recorded, such as a slight laxative effect and flatulence from both inulin-derived oligosaccharides and galacto-oligosaccharides; however, this is only the case when significant quantities are consumed, and therefore, overall, the benefit far outweighs any potential drawbacks. To make a prebiotic function effectively, it must be able to pass undigested through the GI tract and to reach its target bacteria in the gut, where it can be fermented. Furthermore, the target bacteria themselves must be present in the gut for there to be any modulatory effect. ${ }^{67}$ Many common foodstuffs such as onions, garlic, and bananas naturally contain oligosaccharides with prebiotic potential ${ }^{68}$ However, it is believed that these polysaccharides are present in a too low concentration to significantly alter the levels of bacteria in the gut. This has led to the initiative of extracting and purifying prebiotics and then fortifying common foodstuffs such as table spreads, drinks, and cereals. ${ }^{68}$ This has been proven to be a less expensive method of modulating the gut microbiome than using probiotics. ${ }^{64}$ Prebiotic compounds can be extracted from plant sources. Another technique to produce galacto-oligosaccharides is to break down lactose, an abundant by-product in the manufacture of dairy goods, using $\beta$-galactosidases ${ }^{65}$ This method consumes substrates that would otherwise have gone to waste as well as can produce the prebiotic.

\section{Probiotics}

Probiotics used in humans are live bacteria and yeasts, which are delivered to the gut via oral ingestion. ${ }^{67}$ They are often ingredients in food products, which have a unique selling point, making them very popular with members of the public, but is there any truth in the usefulness of probiotics? Like prebiotics, to make probiotics effective, they must be resistant to digestion in the upper gut, such that they can reach sections of the bowel where they can seed and grow. ${ }^{67}$ Probiotics have been shown to confer beneficial effects on the host. They compete with pathogenic microbes for nutrients and space to grow, inhibiting pathogenic growth. ${ }^{69}$ Furthermore, some probiotics such as bifidobacteria, but mainly lactobacilli, produce peptides called bacteriocins that have antimicrobial 
properties and are used to kill pathogenic bacteria. ${ }^{70}$ Although several research reports have confirmed that the consumption of probiotics has numerous health benefits, ${ }^{71-74}$ nevertheless, "health authorities have only approved claims on (a) lactose intolerance and lactose digestion and (b) cholesterol reduction mostly because of biomarker deficiency." 75 The risk of myocardial infarction is three times higher in those with a high lipid profile than in those with normal levels of blood lipids. ${ }^{76}$ The cholesterol-reducing ability of probiotics has been extensively studied and has revealed that total plasma cholesterol and low-density lipoprotein cholesterol can be reduced by $7.84 \%$ and $9.27 \%$, respectively. ${ }^{77,78}$ Existing accessible antimicrobial treatments for yeast vaginitis, candidiasis, bacterial vaginosis, and urinary tract infection can often lead to a number adverse drug reactions, such as diarrhea, superinfections, depression, and even renal failure. ${ }^{75}$ Moreover, antimicrobial resistance inclines to decline the usefulness of this therapy over time. ${ }^{17-19}$ Lactobacilli have been shown to create biosurfactants and collagen-binding proteins that inhibit pathogen adhesion to the vaginal wall. This actually explains the reason why the vaginal mucosa is conquered by lactobacilli, making access to pathogens problematic. ${ }^{79}$ Probiotics available in the marketplace for oral health include species of Lactobacillus and Bifidobacterium. ${ }^{80}$ Several studies have demonstrated that Lactobacillus and Bifidobacterium can decrease the oral levels of the cariogenic species Streptococcus mutans. ${ }^{81-84}$ Streptococcus salivarius K12 has also been recognized to generate several proteins that are active against closely related strain (bacteriocins) such as Streptococcus pyogenes and Streptococcus pneumonia and avert repeated pharyngitis, otitis media, and tonsillitis. ${ }^{85,86}$ Microbial $\beta$-galactosidase in yogurt is resistant to gastric acid and supports lactose digestion. ${ }^{75}$ Multiple studies detected that the symptoms of lactose malabsorption improved due to extra production of $\beta$-galactosidase by probiotic cultures. ${ }^{87,88}$ Furthermore, it has been observed that milk containing Lactobacillus acidophilus also aids lactose absorption and shows improvement in lactose-intolerant patients. ${ }^{89}$ Probiotic supplementation can also modify the quantity of colonic microbiota and improve symptoms in lactose-intolerant subjects. ${ }^{90}$

\section{Symbiotics}

A symbiotic is a combination of a prebiotic and a probiotic. ${ }^{91}$ There is a sound logic behind the symbiotic concept; the probiotic component will aid in metabolism and host immunity, whereas the prebiotic selectively stimulates the growth of the probiotic, and other beneficial bacteria already extant in the gut. Overall gut health is positively modulated. The effective- ness of symbiotics has been investigated in several diseases. The symbiotic therapy involving Bifidobacterium longum and Synergy 1 has been shown to have benefits to both Crohn's disease (CD) and ulcerative colitis (UC) patients. B. longum was chosen from a selection of nineteen bifidobacterial strains. This choice was made based on testing for desired characteristics: aerotolerance, acid tolerance, bile salt resistance, adhesion to epithelial cells, and ability to use oligofructose as an energy source, as well as a capacity to withstand freeze-drying and storage. The bacterium that predominated in all categories was B. longum..$^{2}$ Synergy 1 is made from inulin from the chicory plant and oligofructose. ${ }^{67}$ Another important bacterium is Faecalibacterium prausnitzii, which is found in ample quantity ( $5 \%$ of the total bacterial population) in the human intestinal microbiota of healthy adults. ${ }^{93}$ This species is a highly functionally active member of the microbiome, influencing numerous host pathways. ${ }^{94}$ Several intestinal disorders were noticed to contain low numbers of $F$. prausnitzii, particularly in IBD patients. ${ }^{93,95}$ Hence, the number of intestinal F. prausnitzii can be recommended as an indicator of intestinal health. ${ }^{93-95}$ Immunologic dysregulation is the reason of numerous noninfectious human illnesses. The GI tract is the principal location of contact between the "host immune system and microorganisms, both symbiotic and pathogenic." ${ }^{96}$ Intestinal bacteria are considered for the development and function of the immune system. From the clinical, epidemiological, and immunological evidence, it was concluded that the absence of valuable microorganisms that sponsor appropriate immune development leads to the inflammatory responses including IBDs. ${ }^{97}$

\section{Diet-related dysbiosis, coeliac diseases, gluten-free diet (GFD), breast milk, western diet, and polyphenols}

The impact of food on the arrangement of the microbiota has been shown during the preliminary colonization phase: breastfed newborns have advanced levels of Bifidobacteria spp., whereas formula-fed infants have higher levels of Bacteroides spp., as well as amplified Clostridium coccoides and Lactobacillus spp. ${ }^{98}$ The microbiota was assumed to maintain a relatively steady state all the way through life after the postnatal epoch. Nevertheless, quite a recent study have revealed that dietary influences modify the microbial community, resulting in biological deviations to the host. ${ }^{99}$ It is extensively documented that the intestinal microbiota plays a role in preventing the commencement and continuation of intestinal inflammation in an ample number of chronic intestinal diseases. ${ }^{100}$ Several studies reported that Celiac disease $(\mathrm{CeD})$ patients with GI indicators are also recognized 
to have an altered microbiota. ${ }^{101-104}$ It has been observed that the numbers of Bifidobacterium spp. and B. longum were significantly reduced, and the numbers of Bacteroides spp. were increased in stools and duodenal biopsies of CeD patients, untreated and treated with a GFD, compared with control subjects. ${ }^{101,102}$ In addition, specific bacterial strains isolated from patients with active and nonactive $\mathrm{CeD}$ have been shown to have augmented virulence features. These outcomes recommended that microbiota modifications are of significance to the inflammatory status characteristics of the vigorous stage of the disease. These alterations could perform both a secondary role by enraging $\mathrm{CeD}$ pathogenesis and engendering a vicious circle and a primary role in contributing to disease onset. ${ }^{100}$ Diet is the most important eco-friendly factor impelling gut microbiota multiplicity and functionality, which might be pertinent to subjects following dietary remedies. The $\mathrm{CeD}$ is an enteropathy caused by an atypical immune response to cereal gluten proteins, and the solitary therapy is the obedience to a GFD. ${ }^{105}$ Human milk is a comprehensive source of sustenance for the newborn. ${ }^{106}$ Human microbial colonization commences at birth and progresses and modifies in species profusion for $\sim 3$ years while waiting for the microbiota to grow into adult form. Toddlers go through noteworthy, evolving ups and downs of microbial colonization that encourage their health status as well as their immune system. ${ }^{107}$ Exclusive breastfeeding for 6-months encourages the infant's progress towards the multiplying of a defensive intestinal microbiota. The milk glycans among the many components of milk have been identified as chauffeurs of microbiota development and overall gut health because of its inherent properties of pleiotropic functions, conferring protection against infectious diseases. ${ }^{106}$ Furthermore, intestinal permeability in preterm infants characterizes a life-threatening balance between the absorption of nutritional agents and protection from dangerous pathogens. Newborns who received either exclusive or a majority of feeding as human milk revealed significantly lower intestinal permeability when compared to infants receiving minimal or no human milk in postnatal days. ${ }^{108}$ Western diet, which contains highly refined haphazard foods with poor nutritional quality essentially constituting sugar and fat, causes dysbiosis that upsets both host GI tract metabolism and immune homeostasis. ${ }^{109-111}$ Another study highlighted typical Western diet converts the microbiota composition shifting to an overgrowth of Firmicutes including Clostridium innocuum, Eubacterium dolichum, Catenibacterium mitsuokai, and Enterococcus spp., as well as a significant reduction in several Bacteroides spp.; however, traditional food regimes rich in plant polysac- charides are linked with a Prevotella enterotype..$^{52,112}$ It also reported that such a typical diet can cause $71 \%$ upsurge in plasma levels of endotoxins, proposing that endotoxemia may progress in folks with GI barrier dysfunction associated with dysbiosis. ${ }^{113}$ Dietary polyphenols extant in a wide-range of vegetables and fruits have been associated with positive health benefits. ${ }^{114,115}$ It has also been reported that variances in the dispersal of bacteria are linked with dietary habits and this in reality provocates and promotes the host to be exposed to microbial metabolites. ${ }^{115}$ Another group of scientist revealed that the gut microbiome of children living in remote West African countries was significantly different from that of the children of the same age from the most sophisticated European countries. ${ }^{116}$ Similar observation of differences in gut microbiome was found between communities, in rural and urban areas, and residents in non-industrialized and industrialized societies. ${ }^{117,118}$ Multiple studies reported that dietary polyphenols are entrusted to conserve the intestinal health by protecting the gut microbial equilibrium through the encouragement of the development of beneficial bacteria (ie, lactobacilli and bifidobacteria) and the inhibition of pathogenic bacteria, wielding prebiotic-like properties. ${ }^{119-125}$

\section{Fecal microbiota transplantation (FMT)}

FMT (or bacteriotherapy) is the relocation of stool from a healthy giver into the GI tract with the determination of treating recurrent Clostridium difficile colitis. ${ }^{126} \mathrm{C}$. difficile infection (CDI) is the leading cause of antibiotic-associated diarrhea, and the infection rates are increasing. ${ }^{127-129} \mathrm{CDI}$ treatment choices are restricted and seem to lose efficacy due to resistance. Recurrent disease is particularly puzzling; extended treatment with oral vancomycin (Eli Lilly and Company, Indianapolis, IN, USA) is becoming increasingly common, but is expensive. ${ }^{127}$ The emergence of the hypervirulent $C$. difficile strain has been related to a rise in disease severity, with mortality reported in up to $6.9 \%$ of cases. ${ }^{130}$ The associated economic burden is also significant. ${ }^{128}$ Nosocomial CDI upsurges the cost of treatment by fourfold, translating to a cost reported up to $\$ 4.8$ billion/year in the USA. ${ }^{131,132}$ FMT embraces substantial potential as a therapy for recurrent CDI with very minimum cost, but still requires more research. ${ }^{127-129}$

\section{Microbiome and its relationship to disease IBD}

IBD is a general term used to define many conditions that cause inflammation of the GI tract, with the two main forms being $\mathrm{UC}$ and $\mathrm{CD}$. Both are chronic illnesses that 
are characterized by inflammation, which often goes into remission and then flares up throughout the sufferer's lifetime. A study conducted in Germany tested the hypothesis of a genetic link in IBD. Monozygotic twins were found to have a tenfold increased risk of developing the condition than dizygotic twins, emphasizing a strong genetic link in sufferers of IBD, especially CD. ${ }^{133}$ Recent advances have provided substantial insight into genetic relation with IBD. Epidemiological data shows the prevalence among different geographical areas, ethnic groups, familial predisposition, and concordance in twins. ${ }^{134,135}$ IBD is a peaks-and-valleys disease categorized by diarrhea, abdominal pain, and weight loss. ${ }^{135}$ Recently, it has been observed that IBD has a strong correlation with sleep, circadian rhythms, and melatonin. ${ }^{136}$ Sleep disorders have become a global issue; currently, in modern society, lack of sleep, shift work, or circadian misalignment is an extremely common issue. The total sleep time has increasingly declined over the last 25 years as the change of work environment, frequent long flights, and mobility have been internationally altered and posed a challenge to human circadian homeostasis. ${ }^{137,138}$ Insomnia and other sleep disorders are associated with many serious adverse health miseries, economic consequences, and, furthermost significantly, has amplified all-cause mortality. ${ }^{139}$ It has been observed that there is a strong correlation between sleep and the immune system. Although the total issue regarding sleep and immunity is complex and poorly understood, ${ }^{139}$ sleep strengthens immune function ${ }^{131}$ and deprivation has been shown to have damaging effects on the immune system and can lead to leukocytosis and an increase in natural killer cells, which can lead to increased inflammatory cytokine production. ${ }^{140-142}$ Environmental factors were also considered as an indispensable gear of the pathogenesis of IBD and chiefly accountable for its mounting incidence worldwide. ${ }^{143}$ Many environmental hazardous aspects have been identified "including smoking, appendectomy, oral contraceptives, diet, breastfeeding, infections/ vaccinations, antibiotics, and childhood hygiene."142 None of these environmental factors were isolated as the definite cause of IBDs. ${ }^{143,144}$ The identification of various alterations of the gut microbiota composition in IBD has enabled using very advanced next-generation sequencing technology. ${ }^{145}$ Alterations in the ecological system have been reported within the gut, that is, intestinal microbes and the immune system. ${ }^{146,147}$ "The most consistent observation in IBD is reduced bacterial diversity, a decrease of Firmicutes, and an increase of Proteobacteria." ${ }^{145}$ Although many factors such as "host, genetic, and environmental" influences have been identified as for the pathogenesis of IBD, ${ }^{140}$ currently, only smoking has been identified as the most potential and specific environmental factor for the onset of IBD. ${ }^{148-150}$

\section{CD}

$\mathrm{CD}$ is a patchy transmural inflammation in the GI tract, which is found anywhere from the mouth to the rectum. Typically, the most common sites of inflammation are the distal sections of the small intestine such as the ileum and the colon. The severity of the condition can range from no symptoms at all (during times of remission) to acutely lifethreatening. ${ }^{151}$ Epidemiologically, the condition is most prevalent in the developed nations of Europe and the USA, with significantly lower incidence in the Southern Hemisphere. ${ }^{152}$ Although the pathology and physiology involved in CD are not completely understood, there appear to be many factors that predispose to the condition: bacterial activity in the gut, genetic susceptibility, and irregular immune response. ${ }^{151,152}$ The inflammatory response found in CD is defined by the release of type 1 helper T-cell cytokines, namely tumor necrosis factor-alpha (TNF- $\alpha$ ), interferon gamma (IFN- $\gamma$ ), and IL-12. ${ }^{151}$ The traditional treatments for CD are steroids, anti-inflammatory drugs, and, in particularly severe cases, surgical resection of inflamed portions of the bowel, with $\sim 70 \%$ of sufferers requiring surgical intervention during their lifetime. ${ }^{151}$ However, there is an increasing interest in alternative therapies involving probiotics, prebiotics, and symbiotics. Probiotics have been extensively tested, with varying results. For example, Lactobacillus GG was found not to reduce the rates of recurrence in the disease, and Nissle 1917, a strain of Escherichia coli, was found to promote quicker remission of the disease, but not to affect the rates of remission between subjects. ${ }^{67}$ The use of prebiotics, on the other hand, has not been explored as deeply, and the few studies conducted have been little more than pilot studies. Symbiotics have shown more potential than either probiotics or prebiotics in isolation. A double-blind randomized control trial was conducted on 35 patients with $C D$ to ascertain the effectiveness of the symbiotic therapy comprising B. longum and Synergy $1 .{ }^{153}$ In the present study, appropriately selected subjects ingested either the symbiotic or a placebo every day, for the duration of 6 months. Patients were required to keep a bowel habit diary for the duration of the test. Furthermore, at the beginning, 3 months, and finally 6 months into the study, patients were required to undertake a Crohn's disease activity index (CDAI) assessment, fill out an IBD lifestyle questionnaire, and undergo flexible sigmoidoscopy or colonoscopy. Biopsies were taken for histological analysis. The study found that there were significant improvements in the CDAI and 
histological scores of the symbiotic group compared with the placebos. The numbers of $B$. longum in the gut mucosa were found in higher abundance coupled with larger populations of other bifidobacteria. Another important finding was that after 3 months of therapy, the levels of TNF- $\alpha$ (the principal inflammatory cytokine in $\mathrm{CD}$ ) were markedly reduced in the symbiotic group. However, the reduction in TNF- $\alpha$ was not as significant at the 6-month check-up. Overall, this study showed that symbiotics have the potential to be a viable treatment for $\mathrm{CD}$, which may become more commonplace with time and development.

\section{Ulcerative colitis}

$\mathrm{UC}$ is one of the two main forms of IBD and is characterized by the formation of ulcers in the lining of the colon and rectum, with patients usually presenting with diarrhea, and with mucus and blood in their stools. ${ }^{154}$ It is distinct from $\mathrm{CD}$ in terms of site, presentation, and histology. The condition also exhibits more of a type 2 helper T-cell-mediated response, with the production of cytokines such as TNF- $\alpha$, IL-1 $\alpha$, IL-1 $\beta$, IL-5, IL-8, and IFN- $\gamma \cdot{ }^{91}$ These cytokines recruit neutrophils and monocytes into the mucosa via chemotaxis. As with $\mathrm{CD}$, the etiology is not fully understood, but there is evidence that points to an inappropriate inflammatory response to the gut microbiome. The main classes of drugs used to treat UC are aminosalicylates, corticosteroids, and immunosuppressant, with many patients eventually requiring a colectomy. ${ }^{154}$ Probiotics such as VSL\#3 (a combination of eight different probiotic bacteria) were found to induce remission in $93 \%$ of subjects compared with $36 \%$ of the placebo group. Furthermore, the rates of relapse were considerably higher $(73 \%)$ in the placebo group and only $21 \%$ to those on the probiotic course. These are quite convincing figures to the effectiveness of VSL\#3; however, it is worth noting that this study was conducted on a cohort of children and adolescents, and the efficacy in adults may not necessarily be the same. ${ }^{155}$ Multiple studies reported that still there is doubt regarding VSL\#3 efficacy and thereafter more research is suggested. ${ }^{156-158}$ As with $\mathrm{CD}$, the combination therapy of $B$. longum and Synergy 1 has been tested on UC patients. After 4 weeks of therapy, the symbiotic group was found to have improved sigmoidoscopy scores and substantially reduced levels of IL- $1 \alpha$ and TNF- $\alpha$ (which are usually elevated in UC patients). A drop in the concentrations of inducible human beta defensins (hBD) was also recorded in the symbiotic group. This is a strong indicator that the inflammation was reduced, as hBD is only produced and released by epithelial tissue when inflamed. It was also noted that the numbers of bifidobacteria in the gut had increased by $\sim 42$ times their original number. ${ }^{152}$ Overall, there was an improvement in bowel activity and positive clinical findings that lay down a foundation for further development of symbiotic treatment.

\section{Irritable bowel syndrome (IBS)}

IBS is a chronic illness characterized by the presence of abdominal pain or discomfort, which may be associated with an increased frequency of defecation and/or accompanied by a change in bowel habit as stated in the National Institute for Health and Clinical Excellence Guidelines. ${ }^{159}$ The etiology of this condition is poorly understood, with possible causes ranging from mal-fermentation of food substrates to psychosocial factors such as stress. ${ }^{160}$ However, it is noted that almost half of the IBS sufferers can identify a definitive event before their symptoms began, for example, surgery, the use of antibiotic drugs, or a spell of gastritis. These are all known to disturb the gut microbiome; therefore, it is hypothesized that this disruption to the bacteria is key to the pathogenesis of IBS. ${ }^{161}$ Investigations have shown that the composition of the microbiome in IBS patients differs from the norm with a higher presence of facultatively anaerobic microorganisms such as Streptococcus spp., E. coli, and Proteus spp. Conversely, lactobacilli and bifidobacterial populations were reduced compared with nonsufferers. ${ }^{161}$ Due to the potential importance of the microbiome in this condition, the idea to modulate it with probiotics and prebiotics presents itself. Many studies have been conducted, but the results are yet being not conclusive, but it shows some promise.

\section{Bacteria in the body over time Neonates}

The gut microbiome, and principally the study of its ancestries in neonates, have become subtopics of great curiosity within the arena of genomics. ${ }^{162}$ The human body does not develop a microbiome until after birth; the sterile nature of the womb prevents microbial colonization until birth. It has been shown in studies conducted in Finland, ${ }^{163}$ as well as in India, ${ }^{164}$ that the method of delivery affects the composition and development of the microbiome. Colonization of mucosa in the digestive, respiratory, urogenital tracts, as well as the skin, begins at, or perhaps even before, the time of birth when a newborn is exposed to a mother's microbiota. ${ }^{165}$ Beforehand it was believed that the utero environment was mostly sterile and that a fetus was not colonized with bacteria until the time of birth. ${ }^{165}$ Babies born by natural means, that is, gain their bacteria from the vaginal tract and fecal matter of the mother, resulting in a more regular and 
healthy microbiome. The species most commonly found in this community are Acinetobacter spp., Bifidobacterium spp., and Staphylococcus spp. On the other hand, the species of bacteria found in babies who were delivered by caesarean section (C-section) are more influenced by bacteria from the mother's skin and the general environment. There is also more chance of unwanted opportunistic invaders colonizing the newborn, to occupy niches that would normally have been inhabited by commensals. Prevailing species in C-section neonates were Citrobacter spp., E. coli, and C. difficile. A notable deficit in bifidobacterial species was also detected. These organisms are known to be very beneficial to the human host. It was also found that Bacteroides spp., which usually colonize a newborn within 3-10 days from birth, ${ }^{31}$ were still present in very low numbers, even 6 months into the life of the child, showing a significant delay in colonization. It has been suggested that this departure from normal gut microbiota composition and delayed colonization of beneficial commensals in babies, due to procedures such as $\mathrm{C}$-sections, which need extra antiseptic measures for surgical interventions, as well as a general culture of sanitation and hygiene, has contributed to the allergy burden carried by many Western nations. Recent study pigeonholed a placental microbiome profile and found that nonpathogenic commensal microbiota from the Firmicutes, Tenericutes, Proteobacteria, Bacteroidetes, and Fusobacteria phyla. ${ }^{166}$ Thereafter, it was reported that within the first week of life, the full-term neonatal gut microbiome is largely colonized by Actinobacteria, Proteobacteria, Bacteroidetes, and, much less, Firmicutes phyla. ${ }^{165,166}$ Oversterilizations of our environment, a lower incidence of disease, as well as changes to diet have resulted in lowered exposure to pathogens and antigens and have led to a change in the communities of friendly bacteria that live inside humans. This has possibly led to higher incidences of atopic conditions and leads to the concept of good dirt and that commensal bacteria in early life can defend against future occurrences of allergy. ${ }^{167}$ Breast milk has been found to have significant prebiotic properties to the microbiome of infants. ${ }^{168,169}$ Oligosaccharides constitute the third highest concentration of all nutrients that make up breast milk. Mammalian enzymes are unable to digest oligosaccharides, which led to the thinking that these carbohydrates were there to satisfy the nutritional needs of commensal bacteria, rather the child itself. ${ }^{170-172}$ In an experiment, it was shown that the growth of two strains of bifidobacteria, B. longum ATCC 15697 and B. longum JCM 7007, was promoted when given human milk oligosaccharides (HMOs). Conversely, when HMOs were supplied to Clostridium perfringens, a pathogen that is one of the most common causes of food poisoning, an inhibitory effect was noted. ${ }^{173}$ Finally, the maternal microbiota outlines the immune scheme of the progenies. Maternal colonization reprograms intestinal transcriptional silhouettes of the descendants, including amplified expression of genes encoding epithelial antibacterial peptides and metabolism of microbial molecules. ${ }^{174}$

\section{The elderly}

The microbiome changes significantly as time passes and the age of the human host increases. There has been found to be greater differences in the gut communities of individuals aged $>65$ years, than that in younger adults. ${ }^{175,176}$ This may be attributed to a greater variation in diets of geriatrics dependent on their social situation and environment. ${ }^{10,177}$ An experiment was conducted - a test group of elderly subjects (mean age $=78$ years) was selected and classified into four groups, ranging from community-residing individuals to those in long-term residential care, two ends of a spectrum. A small number of young healthy adults (mean age $=36$ years) were also included in the study for comparison purposes. ${ }^{177}$ Food diaries of dietary intake were kept by each individual, and an analysis of bacteria in their fecal material was conducted. It was found that community-dwelling subjects had the healthiest microbiomes, which were akin to those of the younger cohort of test subjects. ${ }^{177}$ On the other hand, microbiomes of the long-term residential group were the most removed from those of a healthy adult, with a lower diversity of the species of bacteria present. ${ }^{177}$ An analysis for SCFA production was also conducted, which showed that the bacteria of community subjects possessed more genes that coded for enzymes that produce SCFA than those of long-term residents. ${ }^{177}$ When this data is compared with the diets of the subjects, it becomes more apparent from where this disparity stems. ${ }^{177}$ Most community geriatric diets came under the category of high fiber/low fat, whereas long-term subjects fell under low fiber/ high fat, with the biggest differences in food intake revolving around fruit, vegetables, and meat. ${ }^{110,177,178}$ This shows that diverse and healthy diet results in a similarly positive microbiome and vice versa. Another study has shown that the gut bacteria composition of centenarians differs significantly from that of young or elderly humans. ${ }^{179}$

\section{Conclusion}

A multiplicity of studies involving the gut microbiome has come to a convergent conclusion that commensal bacterium in the human body plays an undeniably important role in host physiological functions. They are involved in metabolizing 
foods, which allows the body to reclaim nutrients that would otherwise be lost as SCFAs such as butyrate. The microbiota has also been shown to provide protection from many chronic diseases of the gut, and they truly deserve the nickname of friendly bacteria.

\section{Disclosure}

The authors report no conflicts of interest in this work.

\section{References}

1. Lederberg J, McCray AT [webpage on the Internet]. 'Ome sweet' omics - a genealogical treasury of words. Scientist. 2001;15:8. Available from: http://www.the-scientist.com/?articles.view/articleNo/13313/ title/-Ome-Sweet--Omics---A-Genealogical-Treasury-of-Words/. Accessed September 19, 2016.

2. Sin D, Sze M, Hogg J. Bacterial microbiome of lungs in COPD. Int J Chron Obstruct Pulmon Dis. 2014;9(1):229-238.

3. Grice EA, Segre JA. The human microbiome: our second genome. Annu Rev Genomics Hum Genet. 2012;13:151-170.

4. Grice EA, Segre JA. The skin microbiome. Nat Rev Microbiol. 2011; 9(4):244-253.

5. Ursell LK, Metcalf JL, Parfrey LW, Knight R. Defining the human microbiome. Nutr Rev. 2012;70 (Suppl 1):S38-S44.

6. Turnbaugh PJ, Ley RE, Hamady M, Fraser-Liggett CM, Knight R, Gordon JI. The human microbiome project. Nature. 2007;449:804-810.

7. Savage DC. Microbial ecology of the gastrointestinal tract. Annu Rev Microbiol. 1977;31:107-133.

8. NIH HMP Working Group, Peterson J, Garges S, et al. The NIH Human Microbiome Project. Genome Res. 2009;19(12):2317-2323.

9. Donohoe DR, Garge N, Zhang X, Sun W. The microbiome and butyrate regulate energy metabolism and autophagy in the mammalian colon. Cell Metab. 2011;13(5):517-526.

10. Bianconi E, Piovesan A, Facchin F, et al. An estimation of the number of cells in the human body. Ann Hum Biol. 2013;40(6):463-471.

11. Rosner JL. Ten times more microbial cells than body cells in humans? Microbe. 2014;9(2):47.

12. Institute of Medicine (US) Forum on Microbial Threats. Microbial Evolution and Co-Adaptation: A Tribute to the Life and Scientific Legacies of Joshua Lederberg: workshop summary [webpage on the Internet]. Washington, DC: National Academies Press; 2009. Available from: http://www.ncbi.nlm.nih.gov/books/NBK45714/. Accessed August 20, 2016.

13. Cabral JPS. Water microbiology. Bacterial pathogens and water. Int $J$ Environ Res Public Health. 2010;7(10):3657-3703.

14. Saxena G, Bharagava RN, Kaithwas G, Raj A. Microbial indicators, pathogens and methods for their monitoring in water environment. $J$ Water Health. 2015;13(2):319-339.

15. Farooqui A, Khan A, Kazmi SU. Investigation of a community outbreak of typhoid fever associated with drinking water. BMC Public Health. 2009;9:476.

16. Sartelli M, Weber DG, Ruppé E, et al. World J Emerg Surg. 2016;11:33.

17. Haque M, Rahman NIA, Zulkifli Z, Ismail S. Antibiotic prescribing and resistance: knowledge level of medical students of clinical years of University Sultan Zainal Abidin, Malaysia. Ther Clin Risk Manag. 2016;12:413-426.

18. Hoque R, Mostafa A, Haque M. Intern doctors' views on the current and future antibiotic resistance situation of Chattagram Maa O Shishu Hospital Medical College, Bangladesh. Ther Clin Risk Manag. 2015;11:1177-1185

19. Hoque R, Mostafa A, Haque M. Insight of medical students of clinical years to antimicrobials prescribing and resistance in private medical school, Chittagong, Bangladesh. J Young Pharm. 2016;8(4): $447-455$
20. Miller G, Fischer DK. Beneficial effects of human viruses. Yale J Biol Med. 1981;54(1):57-63.

21. Bryce K. Fungi: Ecological Importance and Impact on Humans. Chichester: John Wiley \& Sons Ltd; 2011.

22. Relman DA, Falkow $\mathrm{S}$. The meaning and impact of the human genome sequence for microbiology. Trends Microbiol. 2001;9:206-208.

23. Relman DA. New technologies, human-microbe interactions, and the search for previously unrecognized pathogens. J Infect Dis. 2002;186:S254-S258.

24. Baugh RF, Baugh AD. Infection, causation and indigenous flora. JAller Ther. 2012;3:e104.

25. Sekirov I, Finlay B. Human and microbe: united we stand. Nat Med. 2006;12(7):736-737.

26. Phillips ML. Gut reaction: environmental effects on the human microbiota. Environ Health Perspect. 2009;117(5):A198-A205.

27. Institute of Medicine (US) Food Forum. The Human Microbiome, Diet, and Health: workshop summary [webpage on the Internet]. Washington (DC): National Academies Press; 2013. Available from: http://www. ncbi.nlm.nih.gov/books/NBK154093/. Accessed September 21, 2016.

28. Institute of Medicine (US) Forum on Microbial Threats. Ending the War Metaphor: The Changing Agenda for Unraveling the Host-Microbe Relationship: workshop summary [webpage on the Internet]. Washington (DC): National Academies Press; 2006. Available from: http:// www.ncbi.nlm.nih.gov/books/NBK57060/. Accessed September 21, 2016.

29. Forum on Microbial Health; Board on Global Health; Institute of Medicine. Microbial Ecology in States of Health and Disease: workshop summary [webpage on the Internet]. Washington (DC): National Academies Press; 2014. Available from: http://www.ncbi.nlm.nih.gov/ books/NBK189983/. Accessed September 21, 2016.

30. Institute of Medicine (US) Forum on Microbial Threats. The Social Biology of Microbial Communities: workshop summary [webpage on the Internet]. Washington (DC): National Academies Press; 2012. Available from: http://www.ncbi.nlm.nih.gov/books/NBK154544/. Accessed September 21, 2016.

31. Wexler HM. Bacteroides: the good, the bad, and the nitty-gritty. Clin Microbiol Rev. 2007;20(4):593-621.

32. Ji B, Nielsen J. New insight into the gut microbiome through metagenomics. Adv Genomics Genet. 2015;5:77-91.

33. Bakhtiar SM, LeBlanc JG, Salvucci E, et al. Implications of the human microbiome in Inflammatory Bowel Diseases. FEMS Microbiol Lett. 2013;342(1):10-17.

34. Jandhyala SM, Talukdar R, Subramanyam C, Vuyyuru H, Sasikala M, Reddy DN. Role of the normal gut microbiota. World J Gastroenterol. 2015;21(29):8787-8803.

35. Belkaid Y, Hand T. Role of the microbiota in immunity and inflammation. Cell. 2014;157(1):121-141.

36. Langdon A, Crook N, Dantas G. The effects of antibiotics on the microbiome throughout development and alternative approaches for therapeutic modulation. Genome Med. 2016;8:39.

37. Guinane CM, Cotter PD. Role of the gut microbiota in health and chronic gastrointestinal disease: understanding a hidden metabolic organ. Therap Adv Gastroenterol. 2013;6(4):295-308.

38. Ettinger G, MacDonald K, Reid G, Burton JP. The influence of the human microbiome and probiotics on cardiovascular health. Gut Microbes. 2014;5(6):719-728.

39. Winglee K, Fodor AA. Intrinsic association between diet and the gut microbiome: current evidence. Nutr Diet Suppl. 2015;7:69-76.

40. Davis CP. Chapter 6: Normal flora [webpage on the Internet]. In: Baron S, editor. Medical Microbiology. 4th ed. Galveston (TX): University of Texas Medical Branch at Galveston; 1996. Available from: https:// www.ncbi.nlm.nih.gov/books/NBK7617/. Accessed October 16, 2016.

41. Macfarlane GT, Macfarlane S. Bacteria, colonic fermentation, and gastrointestinal health. JAOAC Int. 2012;95(1):50-60.

42. Macfarlane S, Hopkins MJ, Macfarlane GT. Bacterial growth and metabolism on surfaces in the large intestine. Microb Ecol Health Dis. 2000;2:64-72. 
43. Gut microbiota for health. Gut microbiota info [webpage on the Internet]. Available from: http://www.gutmicrobiotaforhealth.com/en/ about-gut-microbiota-info/. Accessed February 27, 2017.

44. van der Waaij LA, Harmsen HJ, Madjipour M, et al. Bacterial population analysis of human colon and terminal ileum biopsies with $16 \mathrm{~S}$ rRNA-based fluorescent probes: commensal bacteria live in suspension and have no direct contact with epithelial cells. Inflamm Bowel Dis. 2005; 11:865-871.

45. Marchesi JR. Human distal gut microbiome. Environ Microbiol. 2011;13(12):3088-3102.

46. Macfarlane S, Macfarlane GT. Regulation of short-chain fatty acid production. Proc Nutr Soc. 2003;62:67-72.

47. Institute of Medicine. Dietary, functional, and total fiber. dietary reference intakes for energy, carbohydrate, fiber, fat, fatty acids, cholesterol, protein, and amino acids [webpage on the Internet]. Washington, DC: The National Academic Press; 2005. Available from: https://fnic.nal. usda.gov/sites/fnic.nal.usda.gov/files/uploads/energy_full_report.pdf. Accessed August 31, 2016.

48. Cummings JH. Short chain fatty acids in the human colon. Gut. 1981;22 (9):763-779.

49. Hijova E, Chmelarova A. Short chain fatty acids and colonic health. Bratisl Lek Listy. 2007;108(8):354-358.

50. Cummings JH, Macfarlane GT. The control and consequences of bacterial fermentation in the human colon. J Appl Bacteriol. 1991;70(6):443-459.

51. Kim J, Kundu M, Viollet B, Guan KL. AMPK and mTOR regulate autophagy through direct phosphorylation of Ulk1. Nat Cell Biol. 2001;13(2):132-141.

52. Turnbaugh PJ, Ridaura VK, Faith JJ, Rey FE, Gordon JI. The effect of diet on the human gut microbiome: a metagenomic analysis in humanized gnotobiotic mice. Sci Transl Med. 2009;1(6):1-19.

53. Morrison DJ, Preston T. Formation of short chain fatty acids by the gut microbiota and their impact on human metabolism. Gut Microbes. 2016;7(3):189-200.

54. Chang PV, Hao L, Offermanns S, Medzhitov R. The microbial metabolite butyrate regulates intestinal macrophage function via histone deacetylase inhibition. Proc Natl Acad Sci U S A. 2014;111(6):2247-2252.

55. Nastasi C, Candela M, Bonefeld CM, et al. The effect of short-chain fatty acids on human monocyte-derived dendritic cells. Sci Rep. 2015;5:16148.

56. Vernia P, Fracasso PL, Casale V, et al. Topical butyrate for acute radiation proctitis: randomized, crossover trial. Lancet. 2000;356(9237):1232-1235.

57. Vernia P, Annese V, Bresci G, et al. Topical butyrate improves efficacy of 5-ASA in refractory distal ulcerative colitis: results of a multicenter trial. Eur J Clin Invest. 2003;33(3):244-248.

58. Cox MA, Jackson J, Stanton M, et al. Short-chain fatty acids act as antiinflammatory mediators by regulating prostaglandin E2 and cytokines. World J Gastroenterol. 2009;15(44):5549-5557.

59. Deshmane SL, Kremlev S, Amini S, Sawaya BE. Monocyte chemoattractant protein-1 (MCP-1): an overview. J Interferon Cytokine Res. 2009;29(6):313-326.

60. Bindels LB, Porporato P, Dewulf EM, et al. Gut microbiota-derived propionate reduces cancer cell proliferation in the liver. Br J Cancer. 2012;107(8):1337-1344.

61. Lupton JR. Diet induced changes in the colonic environment and colorectal cancer. Microbial degradation products influence colon cancer risk: the butyrate controversy. J Nutr. 2004;134(2):479-482.

62. Food Quality and Standards Service (AGNS). Food and Agriculture Organization of the United Nations (FAO). FAO Technical Meeting on Prebiotics [webpage on the Internet]; 2007. Available from: https://www.google.com/url? sa=t\&rct=j\&q=\&esrc=s\&source=we $\mathrm{b} \& \mathrm{~cd}=2 \& \mathrm{cad}=\mathrm{rja} \& u a c t=8 \& v e d=0$ ahUKEwiu_4CohOvOAhWK qo8KHSjyCZEQFggtMAE\&url=http $\% 3 \mathrm{~A} \% 2 \mathrm{~F} \% 2 \mathrm{Fwww}$.aat-taa. eu\%2Findex $\% 2$ Fen $\% 2$ Fcompany\%2Fdownload\%2F 1262610500 . html\&usg=AFQjCNHQcmt3Yr7aVimPbXm-1NpO-UNK8Q\&sig2= EpOjN3rnHZ2JJKPkPO6uVQ. Accessed August 31, 2016.
63. Pineiro M, Asp NG, Reid G, et al. J Clin Gastroenterol. 2008;42 (Suppl 3; Pt 2):S156-S159.

64. Macfarlane S, Macfarlane GT, Cummings JH. Review article prebiotics in the gastrointestinal tract. Aliment Pharmacol Ther. 2006; 24(5):701-714.

65. Macfarlane GT, Steed H, Macfarlane S. Bacterial metabolism and health-related effects of galacto-oligosaccharides and other prebiotics. J Appl Microbiol. 2008;104(2):305-344.

66. Felis GE, Dellaglio F. Taxonomy of lactobacilli and bifidobacteria. Curr Issues Intest Microbiol. 2007;8(2):44-61.

67. Macfarlane GT, Macfarlane S. Manipulating the indigenous microbiota in humans- prebiotics, probiotics and symbiotics. In: Fredricks DN, editor. The Human Microbiota: How Microbial Communities Affect Health and Disease. Hoboken, NJ: John Wiley \& Sons Inc.; 2013: 315-334.

68. Manning TS, Gibson GR. Prebiotics. Best Pract Res Clin Gastroenterol. 2004;18(2):287-298.

69. Vyas U, Ranganathan N. Probiotics, prebiotics, and symbiotics: gut and beyond. Gastroenterol Res Pract. 2012;1(2012):1-16.

70. Martinez F, Balciunas E, Converti A, Cotter PD, Pinheiro R, de Souza Oliveira RP. Bacteriocin production by Bifidobacterium spp. A review. Biotechnol Adv. 2013;31(4):482-488.

71. DiRienzo D. Effect of probiotics on biomarkers of cardiovascular disease: implications for heart-healthy diets. Nutr Rev. 2014;72(1):18-29.

72. Gilbert J, Krajmalnik-Brown R, Porazinska DL, Weiss SJ, Knight R. Toward effective probiotics for autism and other neurodevelopmental disorders. Cell. 2013;155(7):1446-1448.

73. Jones ML, Martoni CJ, Prakash S. Oral supplementation with probiotic L. reuteri NCIMB 30242 increases mean circulating 25-hydroxyvitamin D: a post hoc analysis of a randomized controlled trial. J Clin Endocrinol Metab. 2013;98(7):2944-2951.

74. Baek YJ, Lee BH. Probiotics and prebiotics as bioactive components in dairy products, In: Park YW, editor. Bioactive Components in Milk Dairy Products. New York: Wiley-Blackwell; 2009.

75. Daliri EBM, Lee BH. New perspectives on probiotics in health and disease. Food Sci Hum Wellness. 2015;4(2):56-65.

76. McAuliffe O, Cano RJ, Klaenhammer TR. Genetic analysis of two bile salt hydrolase activities in Lactobacillus acidophilus NCFM. Appl Environ Microbiol. 2005;71(8):4925-4929.

77. Ishimwe N, Daliri EB, Lee BH, Fang F, Du G. The perspective on cholesterol-lowering mechanisms of probiotics. Mol Nutr Food Res. 2015;59(1):94-105.

78. Ooi LG, Liong MT. Cholesterol-lowering effects of probiotics and prebiotics: a review of in vivo and in vitro findings. Int $J \mathrm{Mol} \mathrm{Sci}$. 2010;11(6):2499-2522.

79. Waigankar S, Patel V. Role of probiotics in urogenital healthcare. $J$ Midlife Health. 2011;2(1):5-10.

80. Banas JA, Popp E. Recovery of viable bacteria from probiotic products that target oral health. Probiotics Antimicrob Proteins. 2013;5(3):227-231.

81. Loesche WJ. Role of Streptococcus mutans in human dental decay. Microbiol Rev. 1986;50(4):353-380.

82. Anilkumar K, Monisha A. Role of friendly bacteria in oral health - a short review. Oral Health Prev Dent. 2012;10(1):3-8.

83. Bizzini B, Pizzo G, Scapagnini G, Nuzzo D, Vasto S. Probiotics and oral health. Curr Pharm Des. 2012;18(34):5522-5531.

84. Haukioja A. Probiotics and oral health. Eur J Dent. 2010;4(3):348-355.

85. Di Pierro F, Adami T, Rapacioli G, Giardini N, Streitberger C. Clinical evaluation of the oral probiotic Streptococcus salivarius K12 in the prevention of recurrent pharyngitis and/or tonsillitis caused by Streptococcus pyogenes in adults. Expert Opin Biol Ther. 2013;13(3):339-343.

86. Di Pierro F, Colombo M, Zanvit A, Risso P, Rottoli A. Use of Streptococcus salivarius K12 in the prevention of streptococcal and viral pharyngotonsillitis in children. Drug Healthc Patient Saf. 2014;6:15-20.

87. Ibrahim SA, O'Sullivan DJ. Use of chemical mutagenesis for the isolation of food grade $\beta$-galactosidase overproducing mutants of bifidobacteria, lactobacilli and Streptococcus thermophilus. J Dairy Sci. 2000;83(5):923-930. 
88. van den Bogaard PT, Kleerebezem M, Kuipers OP, de Vos WM. Control of lactose transport, $\beta$-galactosidase activity, and glycolysis by CcpA in Streptococcus thermophilus: evidence for carbon catabolite repression by a non-phosphoenolpyruvate-dependent phosphotransferase system sugar. J Bacteriol. 2000;182(21):5982-5989.

89. Goh YJ, Klaenhammer TR. A functional glycogen biosynthesis pathway in Lactobacillus acidophilus: expression and analysis of the glgoperon. Mol Microbiol. 2013;89(6):1187-1200.

90. Foxx-Orenstein AE, Chey WD. Manipulation of the gut microbiota as a novel treatment strategy for gastrointestinal disorders. Am J Gastroenterol. 2012;1:41-46.

91. van Zanten GC, Knudsen A, Röytiö H, et al. The effect of selected symbiotics on microbial composition and short-chain fatty acid production in a model system of the human colon. PLoS One. 2012;7(10):e47212.

92. Furrie E, Macfarlane S, Kennedy A, et al. Symbiotic therapy (Bifidobacteria longum/synergy 1) initiates resolution of inflammation in patients with active ulcerative colitis. Gut. 2005;54(2):242-249.

93. Miquel S, Martín R, Rossi O, et al. Faecalibacterium prausnitzii and human intestinal health. Curr Opin Microbiol. 2013;16(3):255-261.

94. Li M, Wang B, Zhang M, et al. Symbiotic gut microbes modulate human metabolic phenotypes. Proc Natl Acad Sci USA. 2008;105(6):2117-2122.

95. Foditsch C, Pereira RV, Ganda EK, et al. Oral administration of Faecalibacterium prausnitzii decreased the incidence of severe diarrhea and related mortality rate and increased weight gain in preweaned dairy heifers. PLoS One. 2015;10(12):e0145485.

96. Round JL, Mazmanian SK. The gut microbiome shapes intestinal immune responses during health and disease. Nat Rev Immunol. 2009;9(5):313-323.

97. Izcue $\mathrm{A}$, Hue $\mathrm{S}$, Buonocore $\mathrm{S}$, et al. Interleukin-23 restrains regulatory $\mathrm{T}$ cell activity to drive $\mathrm{T}$ cell-dependent colitis. T cells can induce colitis in IL-23 deficient recipients, suggesting that disease can result in the absence of regulation. Immunity. 2008;28(4):559-570.

98. Fallani M, Young D, Scott J, et al. Intestinal microbiota of 6-weekold infants across Europe: geographic influence beyond delivery mode, breast-feeding, and antibiotics. J Pediatr Gastroenterol Nutr. 2010;51(1):77-84.

99. Brown K, DeCoffe D, Molcan E, Gibson DL. Diet-induced dysbiosis of the intestinal microbiota and the effects on immunity and disease. Nutrients. 2012;4(8):1095-1119.

100. Cenit MC, Olivares M, Codoñer-Franch P, SanzY. Intestinal microbiota and celiac disease: cause, consequence or co-evolution? Nutrients. 2015;7(8):6900-6923.

101. Collado MC, Donat E, Ribes-Koninckx C, Calabuig M, Sanz Y. Specific duodenal and faecal bacterial groups associated with paediatric coeliac disease. J Clin Pathol. 2009;62:264-269.

102. Collado MC, Donat E, Ribes-Koninckx C, Calabuig M, Sanz Y. Imbalances in faecal and duodenal Bifidobacterium species composition in active and non-active coeliac disease. BMC Microbiol. 2008;8:232.

103. Di Cagno R, De Angelis M, De Pasquale I, et al. Duodenal and faecal microbiota of celiac children: molecular, phenotype and metabolome characterization. BMC Microbiol. 2011;11:219.

104. Nistal E, Caminero A, Vivas S, et al. Differences in faecal bacteria populations and faecal bacteria metabolism in healthy adults and celiac disease patients. Biochimie. 2012;94:1724-1729.

105. Sanz Y. Effects of a gluten-free diet on gut microbiota and immune function in healthy adult humans. Gut Microbes. 2010; 1(3):135-137.

106. Pacheco AR, Barile D, Underwood MA, Mills DA. The impact of the milk glycobiome on the neonate gut microbiota. Annu Rev Anim Biosci. 2015;3:419-445.

107. Arrieta MC, Stiemsma LT, Amenyogbe N, Brown EM, Finlay B. The intestinal microbiome in early life: health and disease. Front Immun. 2014;5:427

108. Taylor SN, Basile LA, Ebeling M, Wagner CL. Intestinal permeability in preterm infants by feeding type: mother's milk versus formula. Breastfeed Med. 2009;4(1):11-15.
109. Sekirov I, Russell S, Caetano L, Antunes M, Finlay BB. Gut microbiota in health and disease. Am Physiol Soc. 2010;90:859-904.

110. Conlon MA, Bird AR. The impact of diet and lifestyle on gut microbiota and human health. Nutrients. 2015;7(1):17-44.

111. Myles IA. Fast food fever: reviewing the impacts of the Western diet on immunity. Nutr J. 2014;13:61.

112. Wu GD, Chen J, Hoffmann C, et al. Linking long-term dietary patterns with gut microbial enterotypes. Science. 2011;334(6052):105-108.

113. Pendyala S, Walker JM, Holt PR. A high-fat diet is associated with endotoxemia that originates from the gut. Gastroenterology. 2012;142 (5):1100-1101

114. Dueñas M, Muñoz-González I, Cueva C, et al. A survey of modulation of gut microbiota by dietary polyphenols. Biomed Res Int. 2015;2015:850902.

115. Hullar MAJ, Fu BC. Diet, the gut microbiome, and epigenetics. Cancer J. 2014;20(3):170-175.

116. De Filippo C, Cavalieri D, Di Paola M, et al. Impact of diet in shaping gut microbiota revealed by a comparative study in children from Europe and rural Africa. Proc Natl Acad Sci USA. 2010;107(33):14691-14696.

117. Yatsunenko T, Rey FE, Manary MJ, et al. Human gut microbiome viewed across age and geography. Nature. 2012;486(7402):222-227.

118. Lin A, Bik EM, Costello EK, et al. Distinct distal gut microbiome diversity and composition in healthy children from Bangladesh and the United States. PLoS One. 2013;8(1):e53838.

119. Laparra JM, Sanz Y. Interactions of gut microbiota with functional food components and nutraceuticals. Pharmacol Res. 2010; 61(3):219-225

120. He X, Marco ML, Slupsky CM. Emerging aspects of food and nutrition on gut microbiota. J Agric Food Chem. 2013;61(40):9559-9574.

121. Hervert-Hernandez D, Goñi I. Dietary polyphenols and human gut microbiota: a review. Food Rev Int. 2011;27(2):154-169.

122. Tuohy KM, Conterno L, Gasperotti M, Viola R. Upregulating the human intestinal microbiome using whole plant foods, polyphenols, and/or fiber. J Agric Food Chem. 2012;60(36):8776-8782.

123. Etxeberria U, Fernández-Quintela A, Milagro FI, Aguirre L, Martínez JA, Portillo MP. Impact of polyphenols and polyphenol-rich dietary sources on gut microbiota composition. J Agric Food Chem. 2013;61(40):9517-9533.

124. Cardona F, Andrés-Lacueva C, Tulipani S, Tinahones FJ, QueipoOrtuño MI. Benefits of polyphenols on gut microbiota and implications in human health. J Nutr Biochem. 2013;24(8):1415-1422.

125. Selma MV, Espín JC, Tomás-Barberán FA. Interaction between phenolics and gut microbiota: role in human health. J Agric Food Chem. 2009;57(15):6485-6501.

126. Johns Hopkins Medicine. Gastroenterology and Hepatology. Fecal Transplantation (Bacteriotherapy). Available from: http://www.hopkinsmedicine.org/gastroenterology_hepatology/clinical_services/ advanced_endoscopy/fecal_transplantation.html. Accessed February 27, 2017.

127. Bakken JS, Borody T, Brandt LJ, et al. Treating Clostridium difficile infection with fecal microbiota transplantation. Clin Gastroenterol Hepatol. 2011;9(12):1044-1049.

128. Kassam Z, Lee CH, Yuan Y, Hunt RH. Fecal microbiota transplantation for Clostridium difficile infection: systematic review and metaanalysis. Am J Gastroenterol. 2013;108(4):500-508.

129. Borody TJ, Khoruts A. Fecal microbiota transplantation and emerging applications. Nat Rev Gastroenterol Hepatol. 2011;9(2):88-96.

130. Loo VG, Poirier L, Miller MA, et al. A predominantly clonal multiinstitutional outbreak of Clostridium difficile-associated diarrhea with high morbidity and mortality. NEngl J Med. 2005;353(23):2442-2449.

131. Vonberg RP, Reichardt C, Behnke M, Schwab F, Zindler S, Gastmeier P. Cost of nosocomial Clostridium difficile-associated diarrhea. J Hosp Infect. 2008;70(1):15-20.

132. Dubberke ER, Olsen MA. Burden of Clostridium difficile on the healthcare system. Clin Infect Dis. 2012;55 (Suppl 2):S88-S92.

133. Khor B, Gardet A, Xavier R. Genetics and pathogenesis of inflammatory bowel disease. Nature. 2011;474(7351):307-317. 
134. Ek WE, D'Amato M, Halfvarson J. The history of genetics in inflammatory bowel disease. Ann Gastroenterol. 2014;27(4):294-303.

135. Economou M, Pappas G. New global map of Crohn's disease: genetic, environmental, and socioeconomic correlations. Inflamm Bowel Dis. 2008;14 (5):709-720.

136. Swanson GR, Burgess HJ, Keshavarzian A. Sleep disturbances and inflammatory bowel disease: a potential trigger for disease flare? Expert Rev Clin Immunol. 2011;7(1):29-36.

137. Ali T, Choe J, Awab A, Wagener TL, Orr WC. Sleep, immunity and inflammation in gastrointestinal disorders. World J Gastroenterol. 2013;19(48):9231-9239.

138. Kinnucan JA, Rubin DT, Ali T. Sleep and inflammatory bowel disease: exploring the relationship between sleep disturbances and inflammation. Gastroenterol Hepatol. 2013;9(11):718-727.

139. Gamaldo CE, Shaikh AK, McArthur JC. The sleep-immunity relationship. Neurol Clin. 2012;30(4):1313-1343.

140. Sookoian S, Gemma C, Fernández Gianotti T, et al. Effects of rotating shift work on biomarkers of metabolic syndrome and inflammation. $J$ Intern Med. 2007;261(3):285-292.

141. Ranjbaran Z, Keefer L, Stepanski E, Farhadi A, Keshavarzian A. The relevance of sleep abnormalities to chronic inflammatory conditions. Inflamm Res. 2007;56(2):51-57.

142. Van Cauter E, Spiegel K, Tasali E, Leproult R. Metabolic consequences of sleep and sleep loss. Sleep Med. 2008;9(Suppl 1):S23-S28.

143. Danese S, Sans M, Fiocchi C. Inflammatory bowel disease: the role of environmental factors. Autoimmun Rev. 2004;3(5):394-400.

144. Molodecky NA, Kaplan GG. Environmental risk factors for inflammatory bowel disease. Gastroenterol Hepatol. 2010;6(5):339-346.

145. Matsuoka K, Kanai T. The gut microbiota and inflammatory bowel disease. Semin Immunopathol. 2015;37:47-55.

146. DeGruttola AK, Low D, Mizoguchi A. Current understanding of dysbiosis in disease in human and animal models. Inflamm Bowel Dis. 2016;22:1137-1150

147. Morgan XC, Tickle TL, Sokol H, et al. Dysfunction of the intestinal microbiome in inflammatory bowel disease and treatment. Genome Biol. 2012;13(9):R79.

148. Dam AN, Berg AM, Farraye FA. Environmental influences on the onset and clinical course of Crohn's disease-Part 1: an overview of external risk factors. Gastroenterol Hepatol. 2013;9(11):711-717.

149. Mahid SS, Minor KS, Soto RE, Hornung CA, Galandiuk S. Smoking and inflammatory bowel disease: a meta-analysis. Mayo Clin Proc. 2006;81:1462-1471.

150. Higuchi LM, Khalili H, Chan AT, Richter JM, Bousvaros A, Fuchs CS. A prospective study of cigarette smoking and the risk of inflammatory bowel disease in women. Am J Gastroenterol. 2012; 107:1399-1406.

151. Macfarlane S, Bahrami B, Macfarlane GT. Mucosal biofilm communities in the human intestinal tract. Adv Appl Microbiol. 2011;75:111-143.

152. Macfarlane S, Steed H, Macfarlane GT. Intestinal bacteria and inflammatory bowel disease. Crit Rev Clin Lab Sci. 2009;46(1):25-54.

153. Steed H, Macfarlane GT, Blackett KL, et al. Clinical trial: the microbiological and immunological effects of symbiotic consumption - a randomized double-blind placebo-controlled study in active Crohn's disease. Aliment Pharmacol Ther. 2010;32(7):872-883.

154. Crohn's and Colitis UK. Ulcerative Colitis [webpage on the Internet]; 2016. Available from: http://s3-eu-west-1.amazonaws.com/files. crohnsandcolitis.org.uk/Publications/ulcerative-colitis.pdf. Accessed August 31, 2016.

155. Miele E, Pascarella F, Giannetti E, Quaglietta L, Baldassano RN. Effect of a probiotic preparation (VSL \# 3) on induction and maintenance of remission in children with ulcerative colitis. Am J Gastroenterol. 2009;104(2):437-443.

156. NHS. PrescQIPP. Review of probiotic treatment, including VSL\#3® for ileoanal-pouchitis (DROP-List). Bulletin 82, 2014. Available from: http://pad.res360.net/Content/Documents/PresQIPP-bulletin82-probiotics.pdf. Accessed February 27, 2017.
157. Selinger CP, Bell A, Cairns A, Lockett M, Sebastian S, Haslam N. Probiotic VSL\# 3 prevents antibiotic-associated diarrhea in a doubleblind, randomized, placebo-controlled clinical trial. J Hosp Infect. 2013;84(2):159-165.

158. Andrews JM, Tan M. Probiotics in luminal gastroenterology: the current state of play. Intern Med J. 2012;42(12):1287-1291.

159. National Institute for Health and Clinical Excellence (NICE). Irritable bowel syndrome in adults: diagnosis and management [webpage on the Internet]; 2015. Available from: https://www.nice.org.uk/Guidance/ cg61. Accessed August 31, 2016.

160. Vahedi H, Ansari R, Mir-Nasseri MM, Jafari E. Irritable bowel syndrome: a review article. Middle East J Dig Dis. 2010;2(2):66-77.

161. Madden JAJ, Hunter JO. A review of the role of the gut microflora in irritable bowel syndrome and the effects of probiotics. Bri J Nutr. 2002;88 (Suppl 1):67-72.

162. Gritz EC, Bhandari V. The human neonatal gut microbiome: a brief review. Frontiers in Pediatr. 2015;3:17.

163. Grönlund MM, Lehtonen OP, Eerola E, Kero P. Fecal microflora in healthy infants born by different methods of delivery: permanent changes in intestinal flora after cesarean delivery. J Pediat Gastroenterol Nutr. 1999;28(1):19-25.

164. Pandey PK, Verma P, Kumar H, Bavdekar A, Patole MS, Shouche YS. Comparative analysis of fecal microflora of healthy full-term Indian infants born with different methods of delivery (vaginal vs cesarean): Acinetobacter sp. prevalence in vaginally born infants. $J$ Biosci. 2012;37(6):989-998.

165. Aagaard K, Ma J, Antony KM, Ganu R, Petrosino J, Versalovic J. The placenta harbors a unique microbiome. Sci Transl Med. 2014;6(237):237ra65.

166. Adlerberth I, Wold AE. Establishment of the gut microbiota in Western infants. Acta Paediatr. 2009;98:229-238.

167. Okada H, Kuhn C, Feillet H, Bach J. The "hygiene hypothesis" for autoimmune and allergic diseases: an update. Clin Exp Immunol. 2010;160(1):1-9.

168. Houghteling PD, Walker WA. Why is initial bacterial colonization of the intestine important to the infant's and child's health? J Pediatr Gastroenterol Nutr. 2015;60(3):294-307.

169. Guaraldi F, Salvatori G. Effect of breast and formula feeding on gut microbiota shaping in newborns. Front Cell Infect Microbiol. 2012;2:94

170. Marcobal A1, Barboza M, Froehlich JW, et al. Consumption of human milk oligosaccharides by gut-related microbes. J Agric Food Chem. 2010;58(9):5334-5340.

171. Ballard O, Morrow AL. Human milk composition: nutrients and bioactive factors. Pediatr Clin North Am. 2013;60(1):49-74.

172. Wang B, Brand-Miller J. The role and potential of sialic acid in human nutrition. Eur J Clin Nutr. 2003;57(11):1351-1369.

173. Yu ZT, Chen C, Kling DE, et al. The principal fucosylated oligosaccharides of human milk exhibit prebiotic properties on cultured infant microbiota. Glycobiology. 2013;23(2):169-177.

174. Gomez de Agüero M, Ganal-Vonarburg SC, Fuhrer T, et al. The maternal microbiota drives early postnatal innate immune development. Science. 2016;351(6279):1296-1302.

175. Biagi E, Candela M, Fairweather-Tait S, Franceschi C, Brigidi P. Ageing of the human metaorganism: the microbial counterpart. Age. 2012;34(1):247-267.

176. Odamaki T, Kato K, Sugahara H, et al. Age-related changes in gut microbiota composition from newborn to centenarian: a cross-sectional study. BMC Microbiol. 2016;16:90.

177. Claesson MJ, Jeffery IB, Conde S, et al. Gut microbiota composition correlates with diet and health in the elderly. Nature. 2012; 488(7410):178-184.

178. Hughes V. Microbiome: cultural differences. Nature. 2012;492(7427): S14-S15.

179. Biagi E, Nylund L, Candela M, et al. Through ageing, and beyond: gut microbiota and inflammatory status in seniors and centenarians. PLoS One. 2010;5(5):e10667. 
Clinical and Experimental Gastroenterology is an international, peerreviewed, open access, online journal publishing original research, reports, editorials, reviews and commentaries on all aspects of gastroenterology in the clinic and laboratory. This journal is included on PubMed. The manuscript management system is completely online and includes a very quick and fair peer-review system, which is all easy to use. Visit http://www.dovepress.com/testimonials.php to read real quotes from published authors.

Submit your manuscript here: https://www.dovepress.com/clinical-and-experimental-gastroenterology-journal 